\title{
Efficacy of Chitosan Paste as Intracanal Medication Against Enterococcus Faecalis and Candida Albicans Biofilm Compared with Calcium Hydroxide in an In Vitro Root Canal Infection Model
}

\section{Pasika Thienngern}

Chulalongkorn University

Anchana Panichuttra

Chulalongkorn University

Chootima Ratisoontorn

Chulalongkorn University

Chuanchom Aumnate

Chulalongkorn University

Oranart Matangkasombut ( $\sim$ oranart.m@chula.ac.th )

Chulalongkorn University

\section{Research Article}

Keywords: Enterococcus faecalis, Candida albicans, Chitosan, intracanal medication, Polyethylene glycol, Propylene glycol

Posted Date: January 17th, 2022

DOI: https://doi.org/10.21203/rs.3.rs-1190318/v1

License: (a) This work is licensed under a Creative Commons Attribution 4.0 International License.

Read Full License 


\section{Abstract \\ Background}

Enterococcus faecalis and Candida albicans are frequently found in persistent endodontic infection and are resistant to calcium hydroxide $\left(\mathrm{Ca}(\mathrm{OH})_{2}\right)$, a commonly used intracanal medication. Thus, an effective and safe antimicrobial medication against such refractory infection is necessary in endodontic retreatment, so we aimed to test the efficacy of chitosan paste against these microorganisms compared with $\mathrm{Ca}(\mathrm{OH})_{2}$ in root canals of extracted human teeth.

\section{Methods}

Thirty-six sterilized human root samples prepared from extracted premolars and upper maxillary incisors were infected with $E$. faecalis for 14 days, while 32 were infected with $C$. albicans for 48 hours, for mature biofilm formation. The samples were assigned to 6 groups of intracanal medications: no medication (negative control), 20\% Polyethylene glycol (PEG), 20\% Propylene glycol (PG), Chitosan+PEG, Chitosan+PG, and $\mathrm{Ca}(\mathrm{OH})_{2}$. After 7 days, intracanal surface dentin was harvested using Protaper next, resuspended, serially diluted and spread on Brain-Heart-Infusion agar (for E. faecalis) and Yeast ExtractPeptone-Dextrose agar (for $C$. albicans) for colony count. Antimicrobial efficacy was determined as percentage of remaining colony forming unit (CFUs) relative to negative control and analyzed using Oneway ANOVA and post-hoc Games-Howell test. The significance level was set at 0.05 .

\section{Results}

For $E$. faecalis, chitosan+PEG and chitosan+PG medication significantly reduced viable bacteria compared with negative control, PEG and PG $(P=0.001,0.003,0.024$, respectively for chitosan+PEG; $P=$ $0.002,0.003,0.014$, respectively for chitosan+PG $)$. Chitosan+PG also had significantly higher antibacterial activity than $\mathrm{Ca}(\mathrm{OH})_{2}(P=0.039)$. For $C$.albicans, chitosan+PEG and chitosan+PG, but not $\mathrm{Ca}(\mathrm{OH})_{2}$, showed a significantly lower level of remaining CFUs compared with negative control $(P=0.013$ and 0.005 , respectively).

\section{Conclusion}

Chitosan paste showed good efficacy as intracanal medication in reducing viable $E$. faecalis and $C$. albicans biofilm during 7 days in root canals. In particular, Chitosan+PG was significantly more effective against $E$. faecalis than $\mathrm{Ca}(\mathrm{OH})_{2}$. Therefore, it could be developed as an effective alternative medication in endodontic retreatment.

\section{Background}


A major factor in endodontic failure in root canal treated teeth is persistent infection $(1,2)$. Thus, it is critical to have effective disinfection of the root canal system. To eradicate microorganisms, intracanal medication is an important part of endodontic treatment that relies on the efficacy of antimicrobial agents (2). Calcium hydroxide $\left(\mathrm{Ca}(\mathrm{OH})_{2}\right)$ has been used as a routine intracanal medication. However, certain microorganisms are still frequently detected in failed endodontic treated teeth, such as Enterococcus faecalis and Candida albicans (3).

E. faecalis is a Gram positive cocci that has a proton pump inhibitor mechanism to tolerate the alkalinity of $\mathrm{Ca}(\mathrm{OH})_{2}$. It can resist to a wide $\mathrm{pH}$ range, up to approximately $\mathrm{pH} 11.5$, and could remain after root canal obturation (4). Thus, $\mathrm{Ca}(\mathrm{OH})_{2}$ has poor effectiveness against $E$. faecalis (5). E. faecalis can also suppress lymphocyte activity, invade dentinal tubules, form biofilm and attach to collagen in serum, which can protect them from destruction (6). C. albicans is another microorganism that has been reported in persistent post-treatment apical periodontitis (7). An important virulence factor of $C$. albicans is the ability to switch between blastospore and hyphal form. This enables it to invade host tissue and avoid phagocytosis by macrophages (8). Thigmotropism allows $C$. albicans to penetrate into deep dentinal tubules(9). C. albicans can form biofilm in 48 hours (10). It can survive in a wide range of $\mathrm{pH}$, high alkaline environment and ecologically harsh conditions, which allow them to cause persistent infection(8).

Chitosan is a natural polysaccharide derived from deacetylation of chitin in crustacean shells. Chitosan has antimicrobial, antifungal properties and enhances wound healing (11). Chitosan can interact with microbial outer cellular components, cell membrane, and cytoplasmic constituents (12). Chitosan also has high biocompatibility and low toxicity; thus, it could serve as a good alternative medication in endodontic treatment. Chitosan showed inhibitory effect on planktonic form and biofilm of $E$. faecalis and $C$. albicans (13) (14). Our group has previously showed that certain derivatives of chitosan are effective against $E$. faecalis and common oral Candida species, including $C$. albicans $(15)(16,17)$ In particular, we showed that $1700 \mathrm{kDa}$ and $2100 \mathrm{kDa}$ chitosan are effective against $E$. faecalis, but they require a long contact time (over 1 hour) (15). Thus, these chitosan derivatives are promising to be used as intracanal medication.

In order to formulate chitosan into intracanal medication, Polyethylene glycol (PEG) and Propylene glycol (PG) can be used as vehicles to deliver intracanal medication through dentinal tubules and apical foramen (18). In addition, a previous study suggested that propylene glycol have antibacterial effect on $S$. mutans, E. faecalis, and E. coli (19). Thus, it may also contribute to antimicrobial activity of the medication. The aim of this study is to develop chitosan paste as intracanal medication and test its antimicrobial activity against $E$. faecalis and $C$. albicans in comparison with $\mathrm{Ca}(\mathrm{OH})_{2}$ in the root canals of extracted human teeth

\section{Methods}


This study was carried out in accordance with Declaration of Helsinki and the proposal was approved by "The Human Research Ethics Committee of the Faculty of Dentistry, Chulalongkorn University, Bangkok, Thailand" (No.055/2020). Informed consent was waived because the donors of the extracted tooth samples were unidentifiable.

\section{Root samples}

Sixty-eight intact premolars and upper maxillary incisors with single straight root canal extracted for orthodontic and periodontitis reasons were collected. Teeth with caries, fractures, cracks or other defects detected by magnifying loupes were excluded. The tooth samples were prepared as described with minor modification (20). All extracted teeth were stored in $0.1 \%$ thymol until prepared for the experiments (20). All soft-tissue remnants on the surfaces, the crowns and the coronal third of roots were removed until each root was $15 \mathrm{~mm}$ long. The root canals were enlarged by using Protaper next size X4 with 300 RPM speed and $2 \mathrm{gcm}$ torque in a rotary handpiece. The samples were irrigated with $3 \mathrm{ml}$ of $2.5 \%$ sodium hypochlorite $(\mathrm{NaOCl})$ followed by $1 \mathrm{ml}$ of $17 \%$ ethylenediaminetetraacetic acid (EDTA) to remove organic and inorganic debris. All samples were irrigated with $5 \mathrm{ml}$ of distilled water to remove any remaining prior irrigants, and autoclaved for $20 \mathrm{~min}$ at $121^{\circ} \mathrm{C}$. The external surfaces were sealed with nail vanish. The samples were divided into 2 groups, 36 were inoculated with $E$. faecalis and 32 were inoculated with $C$. albicans.

\section{Preparation of microbial culture}

E. faecalis (ATCC 29212) was incubated in brain heart infusion (BHI) broth (Himedia, Mumbai, India) at $37 \mathrm{C}^{\circ}$ until log phase. C. albicans (ATCC 90028) was incubated in Yeast extract - peptone-dextrose broth (YPD; Oxoid, UK and HiMedia, India) at $30 \mathrm{C}^{\circ}$ until log phase. The microbial suspension was adjusted to optical density of 0.5 for $E$. faecalis and 0.1 for $C$. albicans at $600 \mathrm{~nm}$ for inoculation into the root canals.

\section{Infection of the root samples}

Log phase culture $(30 \mu \mathrm{l})$ of $E$. faecalis or $C$. albicans was inoculated into the root canals. For E. faecalis, $\mathrm{BHI}$ media was replenished every 48 hours and the samples were incubated for 14 day for mature biofilm formation (21). For $C$. albicans, the root samples were incubated for 48 hours for mature biofilm formation (10). All procedures were carried out in a biosafety cabinet.

\section{Preparation of intracanal medications}

The chitosan powder (1700 KDa, Marine Bio Resources, Samutsakhon, Thailand) was dissolved in 1\% acetic acid (Merck KGaA, Darmstadt, Germany) at $20 \mathrm{mg} / \mathrm{ml}$. The chitosan pastes were prepared by mixing $1 \mathrm{ml}$ of chitosan solution $(20 \mathrm{mg} / \mathrm{ml})$ with $1 \mathrm{ml}$ of Polyethylene glycol (PEG; Krungthepchemi, Bangkok, Thailand) or propylene glycol (PG; Krungthepchemi, Bangkok, Thailand), and $3 \mathrm{ml}$ of distilled water. The final concentration of chitosan was $4 \mathrm{mg} / \mathrm{ml}$ in $20 \%$ PEG or PG. The pastes were sterilized by autoclave. 
$\mathrm{Ca}(\mathrm{OH})_{2}$ intracanal medication was prepared by mixing $0.4 \mathrm{~g}$ of $\mathrm{Ca}(\mathrm{OH})_{2}$ powder (Faculty of dentistry, Chulalongkorn university, Thailand) with $10 \mathrm{ml}$ of distill water. The final concentration of $\mathrm{Ca}(\mathrm{OH})_{2}$ was 40 $\mathrm{mg} / \mathrm{ml}$.

\section{Antimicrobial assessment}

After the specified incubation period, an aliquot of the media from each sample was plated on solid media to check for microbial purity and viability. Root samples infected with $E$. faecalis and those with $C$. albicans were allocated to 6 groups and treated as follow: group I, no medication (negative control); group 2, 20\% PEG; group 3, 20\% PG; group 4, chitosan+PEG; Group 5, chitosan+PG; and group 6, $\mathrm{Ca}(\mathrm{OH})_{2}$. Thirty $\mu \mathrm{l}$ of the assigned medication were applied into each root canal. The root samples were incubated at $37^{\circ} \mathrm{C}$ for $\mathrm{E}$. faecalis and $30^{\circ} \mathrm{C}$ for $\mathrm{C}$. albicans for 7 days. After 7 days, the canals were washed with 3 $\mathrm{ml}$ of sterile distilled water and Protaper next size X4 was used at 300 RPM speed and 2gcm torque to remove the medicament.

Dentin samples from root canal surfaces were harvested by using Protaper next size X5 at 300 RPM speed and $2 \mathrm{gcm}$ torque and collected in $1 \mathrm{ml}$ of phosphate buffered saline solution. After serial dilutions, $100 \mu \mathrm{l}$ of each dilution were plated on BHI agar for $E$. faecalis and YPD agar for $C$. albicans, and incubated for 24 hours at $37^{\circ} \mathrm{C}$ for $\mathrm{E}$. faecalis and 48 hours at $30^{\circ} \mathrm{C}$ for $\mathrm{C}$. albicans. Colonies were counted and calculated into percentage of remaining viable microorganisms relative to the negative control. All experiments were performed in duplicates and repeated 3 times (except for the PEG and PG groups for $C$. albicans where only one sample/group was available for two of the experiments).

\section{Statistical Analysis}

Shapiro-Wilk was used to test for normality of the data. Welch's ANOVA was used to analyze the differences in percentage of remaining viable microorganisms after treatment among groups, followed by Games-Howell test for pairwise comparison. Data were analyzed using IBM SPSS Statistics for Windows, Version 22.0 (IBM, Armonk, New York, USA). A $P$-value of $<0.05$ was considered statistically significant.

\section{Results}

After 7 days of treatment with various medications, the remaining viable microorganisms in the root canals were examined by plate count. The results are shown in Figure 1 for $E$. faecalis and Figure 2 for $C$. albicans. For $E$. faecalis, the average percentage of remaining bacteria in both chitosan+PEG (9.68 \pm $8.6 \%)$ and chitosan+PG $(3.02 \pm 2 \%)$ groups was significantly lower than that of the negative control (102.74 $\pm 26 \%)$, PEG $(85.7 \pm 25.3 \%)$ and PG $(45.28 \pm 17.9 \%)$ groups. $(P=0.001,0.003$, and 0.024 , respectively for chitosan+PEG; $P=0.002,0.003$, and 0.014 , respectively for chitosan+PG). In addition, the $P G$ group showed a significantly lower remaining $E$. faecalis than the negative control $(P=0.015)$. $\mathrm{Ca}(\mathrm{OH})_{2}(46.38 \pm 23.4 \%)$ also had a significantly lower level of remaining $E$. faecalis than the negative control group $(P=0.034)$. Chitosan+PG could reduce the bacteria to a level that is significantly lower than 
the $\mathrm{Ca}(\mathrm{OH})_{2}$ group $(P=0.039)$ but this was not significantly different for the chitosan+PEG group $(P=$ $0.071)$.

For $C$. albicans, both chitosan+PEG $(24.77 \pm 20.5 \%)$ and chitosan+PG $(7.57 \pm 14.6 \%)$ groups harbored significantly lower remaining viable $C$.albicans compared with the negative control $(105.40 \pm 36.5 \%)(P=$ 0.013 and 0.005 , respectively). However, they were not significantly different from PEG $(122.06 \pm 71.7 \%)$ and PG $(95.36 \pm 64.8 \%)$ groups $(P=0.292$, and 0.441 , respectively for chitosan+PEG; $P=0.206$ and 0.293 , respectively for chitosan+PG). In contrast, $\mathrm{PEG}, \mathrm{PG}$, and $\mathrm{Ca}(\mathrm{OH})_{2}(41.19 \pm 38.1 \%)$ were not significantly different from the negative control $(P=0.997,1.00$, and 0.106 , respectively).

\section{Discussion}

In this study, we showed that $1700 \mathrm{kDa}$ chitosan $(4 \mathrm{mg} / \mathrm{ml})$ paste has good antimicrobial efficacy against $E$. faecalis and $C$. albicans biofilm in human root canals. The results suggest that chitosan paste could be developed into an alternative antimicrobial intracanal medication in cases with persistent infection.

Microbiological investigations found a complex community of bacteria and fungi in root canal treated teeth with persistent infection/chronic apical periodontitis. $(1,3)$ This suggests that previous endodontic treatment could not efficiently control these microorganisms. Mechanical instrumentation using larger size rotary instruments may help to remove bacteria and fungi in the root canals, but it cannot completely eradicate microbes in complex root canal structures and excessive instrumentation weakens root dentin (22-25). Thus, effective antimicrobial intracanal medication can overcome the limitations of instrumentation to reduce microorganisms in complex anatomy of the root canals. $\mathrm{Ca}(\mathrm{OH})_{2}$ has been used as routine intracanal medication, but it was not effective against $E$. faecalis and $C$. albicans (2628). Several studies have identified $E$. faecalis and $C$. albicans as important microorganisms using culture-dependent and molecular techniques $(3,29,30)$. For example, a recent study used culturedependent methods and showed that the most prevalent microorganisms in root canal treated teeth was E. faecalis (36.6\%) and followed by C. albicans (20\%) (3). Studies using PCR detected E. faecalis at a prevalence of up to $77 \%$, and $C$. albicans up to $35 \%$, of failed root-filled teeth $(29,30)$. Although $E$. faecalis was not the most abundant bacteria detected by metagenomic studies, it was observed at a greater frequency or proportion in secondary apical periodontitis than primary infection $(31,32)$. Thus, persistence of these microorganisms in the root canals are problematic for endodontic treatment and effective antimicrobial agent against $E$. faecalis and $C$. albicans in root canals is clearly needed $(5,28$, 33).

Our group has previously shown that $1700 \mathrm{kDa}$ chitosan and $2100 \mathrm{kDa}$ chitosan could effectively kill $E$. faecalis at an MBC of $2 \mathrm{mg} / \mathrm{ml}$ (15). However, it needed a long contact time of over $10 \mathrm{~min}$, so it is likely more effective when applied as a root-canal medication rather than as an irrigant. In addition, we also showed that these chitosan derivatives has a minimum fungicidal concentration against $C$. albicans at 4 $\mathrm{mg} / \mathrm{ml}$ (17). Thus, in this study, we formulated $4 \mathrm{mg} / \mathrm{ml}$ of $1700 \mathrm{KDa}$ chitosan in $0.2 \%$ acetic acid into a 
paste for application as an antimicrobial intracanal medication. We used 20\% PEG or PG to confer good flowability for easy handling and enhance penetration into dentinal tubules.

Our results showed that chitosan paste could eliminate more $E$. faecalis than negative control and carrier controls. Chitosan+PG showed greater antibacterial effect against $E$. faecalis biofilm than $P G$, and also greater than $\mathrm{Ca}(\mathrm{OH})_{2}$. Although $E$. faecalis could resist to $\mathrm{Ca}(\mathrm{OH})_{2}$ by a proton pump mechanism, our result showed that $\mathrm{Ca}(\mathrm{OH})_{2}$ was better at reducing viable $E$. faecalis than no medication (26). Since PG could also reduce $E$. faecalis compared with negative control, the combined effect of both chitosan and $P G$ may explain why chitosan+PG is the most effective in this experiment. Chitosan is positively charged and binds the negatively charged microbial cell membrane, while PG can help intracanal medication to penetrate deeper in dentinal tubules and it also has germicidal activity $(19,34,35)$. Similarly, chitosanpropolis nanoparticles was shown to be effective at eliminating $E$. faecalis biofilm after 7 days of medication (36). Thus, chitosan is a promising alternative option for intracanal medication, either alone or in combination with other active ingredients, especially in secondary infection where persistent $E$. faecalis infection may play important roles.

We also found that chitosan paste was effective against $C$. albicans biofilm as both chitosan groups had significantly less remaining viable $C$. albicans than the negative control. We could not detect significant differences among other groups, likely due to the wide variations in the CFU results. For C.albicans, $\mathrm{Ca}(\mathrm{OH})_{2}$ was not significantly different from the negative control group. Our results suggest that $\mathrm{Ca}(\mathrm{OH})_{2}$ is more effective against $E$. faecalis than $C$. albicans. This is concordant with a report by Ercan and colleagues (37).

Microorganisms in biofilm are more tolerant to antimicrobial agents, and this is the form found in the root canals $(8,38)$. Thus, we simulated such biofilm condition in this study using extracted human root specimens inoculated with $E$. faecalis and with $C$. albicans, and allowed sufficient time for mature biofilm formation and penetration in dentinal tubules, ie, 14 days for $E$. faecalis and 48 hours for $C$. albicans, according to previous reports $(38,39)(10)$. Our results showed that chitosan paste could significantly reduce viability of both $E$. faecalis and $C$. albicans in this root canal biofilm model. Thus, it has a great advantage over antibiotics medication, which are effective only against bacteria, but not fungi, and may also lead to tooth discoloration(40). Nevertheless, this in vitro model used single-species biofilm, unlike in vivo conditions where multiple species coexist in a community. Therefore, further studies on multi-species biofilm and clinical trials should be performed in order to develop chitosan paste for future clinical applications.

\section{Conclusion}

In this root-canal biofilm model, chitosan paste could significantly reduce viability of $E$. faecalis and $C$. albicans when used as intracanal medication for 7 days. Thus, it may be an effective medication for endodontic retreatment. 


\section{Abbreviations}

$\mathrm{Ca}(\mathrm{OH})_{2}$

calcium hydroxide

E. faecalis

Enterococcus faecalis

C. albicans

Candida albicans

PEG

Polyethylene glycol

PG

Propylene glycol

ANOVA

Analysis of variance

\section{Declarations}

\section{Ethics approval and consent to participate}

This study was carried out in accordance with Declaration of Helsinki and the proposal was approved by "The Human Research Ethics Committee of the Faculty of Dentistry, Chulalongkorn University, Bangkok, Thailand" (No.055/2020). Informed consent was waived because the donors of the extracted tooth samples were unidentifiable.

Consent for publication

Not applicable

\section{Availability of data and materials}

The data analyzed in the present study are available in supplementary file.

\section{Competing interests}

The authors declare no competing interest

\section{Funding}

This project was supported by Ratchadaphiseksomphot Endowment Fund (to Research Unit on Oral Microbiology and Immunology), Chulalongkorn University.

\section{Authors' contribution}


PT, AP, CR and OM conceptualized and designed the experiments. CA provided suggestions on material selection and preparations. PT performed experiments under supervision of OM and AP. PT and OM analyzed data and wrote the manuscript. All authors have read and approved the manuscript.

\section{Acknowledgements}

This work was supported by Ratchadaphiseksomphot Endowment Fund (Research Unit on Oral Microbiology and Immunology). We would like to thank members of the research unit for their kind assistance.

\section{Author details}

1,2,3 Department of Operative Dentistry, Faculty of Dentistry, Chulalongkorn University. ${ }^{4}$ Metallurgy and Materials Science Research Institute, Chulalongkorn University. ${ }^{5}$ Department of Microbiology and Research Unit on Oral Microbiology and Immunology, Faculty of Dentistry, Chulalongkorn University

\section{References}

1. Nair PN, Sjogren U, Krey G, Kahnberg KE, Sundqvist G. Intraradicular bacteria and fungi in root-filled, asymptomatic human teeth with therapy-resistant periapical lesions: a long-term light and electron microscopic follow-up study. J Endod. 1990;16(12):580-8.

2. Lin LM, Skribner JE, Gaengler P. Factors associated with endodontic treatment failures. J Endod. 1992;18(12):625-7.

3. Pourhajibagher M, Ghorbanzadeh R, Bahador A. Culture-dependent approaches to explore the prevalence of root canal pathogens from endodontic infections. Braz Oral Res. 2017;31:e108.

4. Molander A, Reit C, Dahlen G. The antimicrobial effect of calcium hydroxide in root canals pretreated with 5\% iodine potassium iodide. Endod Dent Traumatol. 1999;15(5):205-9.

5. Basrani B, Tjaderhane L, Santos JM, Pascon E, Grad H, Lawrence HP, et al. Efficacy of chlorhexidineand calcium hydroxide-containing medicaments against Enterococcus faecalis in vitro. Oral Surg Oral Med Oral Pathol Oral Radiol Endod. 2003;96(5):618-24.

6. Love RM. Enterococcus faecalis-a mechanism for its role in endodontic failure. Int Endod J. 2001;34(5):399-405.

7. Waltimo TM, Sen BH, Meurman JH, Orstavik D, Haapasalo MP. Yeasts in apical periodontitis. Crit Rev Oral Biol Med. 2003;14(2):128-37.

8. Siqueira JF, Jr., Sen BH. Fungi in endodontic infections. Oral Surg Oral Med Oral Pathol Oral Radiol Endod. 2004;97(5):632-41.

9. Chua EG, Parolia A, Ahlawat P, Pau A, Amalraj FD. Antifungal effectiveness of various intracanal medicaments against Candida albicans: an ex-vivo study. BMC Oral Health. 2014;14:53.

10. Tyagi SP, Sinha DJ, Garg P, Singh UP, Mishra CC, Nagpal R. Comparison of antimicrobial efficacy of propolis, Morinda citrifolia, Azadirachta indica (Neem) and 5\% sodium hypochlorite on Candida 
albicans biofilm formed on tooth substrate: An in-vitro study. J Conserv Dent. 2013;16(6):532-5.

11. Ballal N, Kundabala M, Bhat K, Acharya S, Ballal M, Kumar R, et al. Susceptibility of Candida albicans and Enterococcus faecalis to Chitosan, Chlorhexidine gluconate and their combination in vitro. Aust Endod J. 2009;35(1):29-33.

12. Raafat $D$, Sahl HG. Chitosan and its antimicrobial potential-a critical literature survey. Microb Biotechnol. 2009;2(2):186-201.

13. Pu Y, Liu A, Zheng Y, Ye B. In vitro damage of Candida albicans biofilms by chitosan. Exp Ther Med. 2014;8(3):929-34.

14. Wang N, Ji Y, Zhu Y, Wu X, Mei L, Zhang H, et al. Antibacterial effect of chitosan and its derivative on Enterococcus faecalis associated with endodontic infection. Exp Ther Med. 2020;19(6):3805-13.

15. Supotngarmkul A, Panichuttra A, Ratisoontorn C, Nawachinda M, Matangkasombut O. Antibacterial property of chitosan against E. faecalis standard strain and clinical isolates. Dent Mater J. 2020.

16. Namangkalakul W, Benjavongkulchai S, Pochana T, Promchai A, Satitviboon W, Howattanapanich S, et al. Activity of chitosan antifungal denture adhesive against common Candida species and Candida albicans adherence on denture base acrylic resin. J Prosthet Dent. 2020;123(1):181 e1- e7.

17. Srimaneepong $V$, Thanamee T, Wattanasirmkit K, Muangsawat S, Matangkasombut O. Efficacy of low-molecular weight chitosan against Candida albicans biofilm on polymethyl methacrylate resin. Aust Dent J. 2021.

18. Cruz EV, Kota K, Huque J, Iwaku M, Hoshino E. Penetration of propylene glycol into dentine. Int Endod J. 2002;35(4):330-6.

19. Nalawade TM, Bhat K, Sogi SH. Bactericidal activity of propylene glycol, glycerine, polyethylene glycol 400, and polyethylene glycol 1000 against selected microorganisms. J Int Soc Prev Community Dent. 2015;5(2):114-9.

20. Del Carpio-Perochena A, Kishen A, Felitti R, Bhagirath AY, Medapati MR, Lai C, et al. Antibacterial Properties of Chitosan Nanoparticles and Propolis Associated with Calcium Hydroxide against Single- and Multispecies Biofilms: An In Vitro and In Situ Study. J Endod. 2017;43(8):1332-6.

21. Taneja S, Kumar P, Malhotra K, Dhillon J. Antimicrobial effect of an oxazolidinone, lantibiotic and calcium hydroxide against Enterococcus faecalis biofilm: An in vitro study. Indian J Dent. 2015;6(4):190-4.

22. Zelic K, Vukicevic A, Jovicic G, Aleksandrovic S, Filipovic N, Djuric M. Mechanical weakening of devitalized teeth: three-dimensional Finite Element Analysis and prediction of tooth fracture. Int Endod J. 2015;48(9):850-63.

23. Usman N, Baumgartner JC, Marshall JG. Influence of instrument size on root canal debridement. J Endod. 2004;30(2):110-2.

24. Koprowicz A, Łęski M, Pawlicka H. Properties of Mechanical Endodontic Instruments and the Quality of the Simulated Canal Preparation. Dent Med Probl 2016;53(4):476-82. 
25. Koprowicz A, Łęski M, Pawlicka HJD, Problems M. Properties of mechanical endodontic instruments and the quality of the simulated canal preparation. Dent Med Probl 2016;53(4):476-82.

26. Evans M, Davies JK, Sundqvist G, Figdor D. Mechanisms involved in the resistance of Enterococcus faecalis to calcium hydroxide. Int Endod J. 2002;35(3):221-8.

27. Turk BT, Sen BH, Ozturk T. In vitro antimicrobial activity of calcium hydroxide mixed with different vehicles against Enterococcus faecalis and Candida albicans. Oral Surg Oral Med Oral Pathol Oral Radiol Endod. 2009;108(2):297-301.

28. Joy Sinha D, Garg P, Verma A, Malik V, Maccune ER, Vasudeva A. Dentinal Tubule Disinfection with Propolis \& Two Extracts of Azadirachta indica Against Candida albicans Biofilm Formed on Tooth Substrate. Open Dent J. 2015;9:369-74.

29. Poptani B, Sharaff M, Archana G, Parekh V. Detection of Enterococcus faecalis and Candida albicans in previously root-filled teeth in a population of Gujarat with polymerase chain reaction. Contemp Clin Dent. 2013;4(1):62-6.

30. Siqueira JF, Jr., Rocas IN. Polymerase chain reaction-based analysis of microorganisms associated with failed endodontic treatment. Oral Surg Oral Med Oral Pathol Oral Radiol Endod. 2004;97(1):8594.

31. Bouillaguet S, Manoil D, Girard M, Louis J, Gaia N, Leo S, et al. Root Microbiota in Primary and Secondary Apical Periodontitis. Front Microbiol. 2018;9:2374.

32. Keskin C, Demiryurek EO, Onuk EE. Pyrosequencing Analysis of Cryogenically Ground Samples from Primary and Secondary/Persistent Endodontic Infections. J Endod. 2017;43(8):1309-16.

33. Waltimo TM, Orstavik D, Siren EK, Haapasalo MP. In vitro susceptibility of Candida albicans to four disinfectants and their combinations. Int Endod J. 1999;32(6):421-9.

34. Olitzky I. Antimicrobial properties of a propylene glycol based topical therapeutic agent. J Pharm Sci. 1965;54(5):787-8.

35. Goy RC, Britto Dd, Assis OBJP. A review of the antimicrobial activity of chitosan. Polímeros: Ciência e Tecnologia. 2009;19:241-7.

36. Parolia A, Kumar H, Ramamurthy S, Davamani F, Pau A. Effectiveness of chitosan-propolis nanoparticle against Enterococcus faecalis biofilms in the root canal. BMC Oral Health. 2020;20(1):339.

37. Ercan E, Dalli M, Dulgergil CT. In vitro assessment of the effectiveness of chlorhexidine gel and calcium hydroxide paste with chlorhexidine against Enterococcus faecalis and Candida albicans. Oral Surg Oral Med Oral Pathol Oral Radiol Endod. 2006;102(2):e27-31.

38. Guerreiro-Tanomaru JM, de Faria-Junior NB, Duarte MA, Ordinola-Zapata R, Graeff MS, TanomaruFilho M. Comparative analysis of Enterococcus faecalis biofilm formation on different substrates. J Endod. 2013;39(3):346-50.

39. Dezhurko-Korol VA, Novozhilova NE, Makeeva IM, Arkhipova AY, Moisenovich MM, Akhmadishina LV, et al. The influence of centrifugation and inoculation time on the number, distribution, and viability of 
intratubular bacteria and surface biofilm in deciduous and permanent bovine dentin. Arch Oral Biol. 2020;114:104716.

40. Lenherr $P$, Allgayer $N$, Weiger R, Filippi A, Attin T, Krastl G. Tooth discoloration induced by endodontic materials: a laboratory study. Int Endod J. 2012;45(10):942-9.

\section{Figures}

\section{E. faecalis}

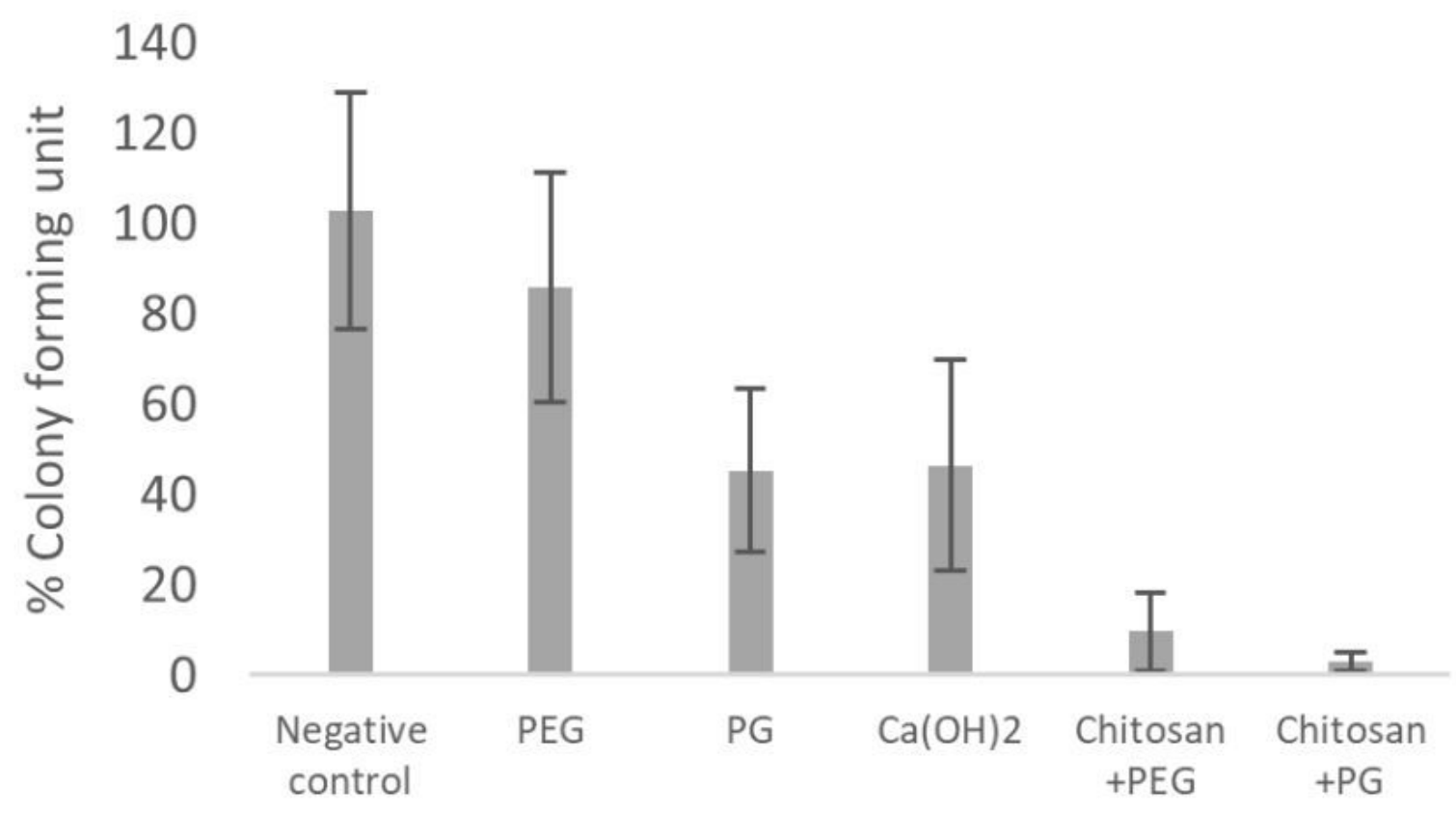

\section{Experiment Groups}

Fig 1

\section{Figure 1}

Percentage of remaining viable $E$. faecalis after treatment with intracanal medication relative to negative control. Negative control group (102.74 $\pm 26 \%), 20 \%$ Polyethylene glycol (PEG) group (85.7 $\pm 25.3 \%), 20 \%$ Propylene glycol (PG) group $(45.28 \pm 17.9 \%)$, calcium hydroxide $\left(\mathrm{Ca}(\mathrm{OH})_{2}\right)$ group $(46.38 \pm 23.4 \%)$, chitosan+PEG group (9.68 $\pm 8.6 \%)$, chitosan+PG group (3.02 $\pm 2 \%)$ 


\section{C. albicans}

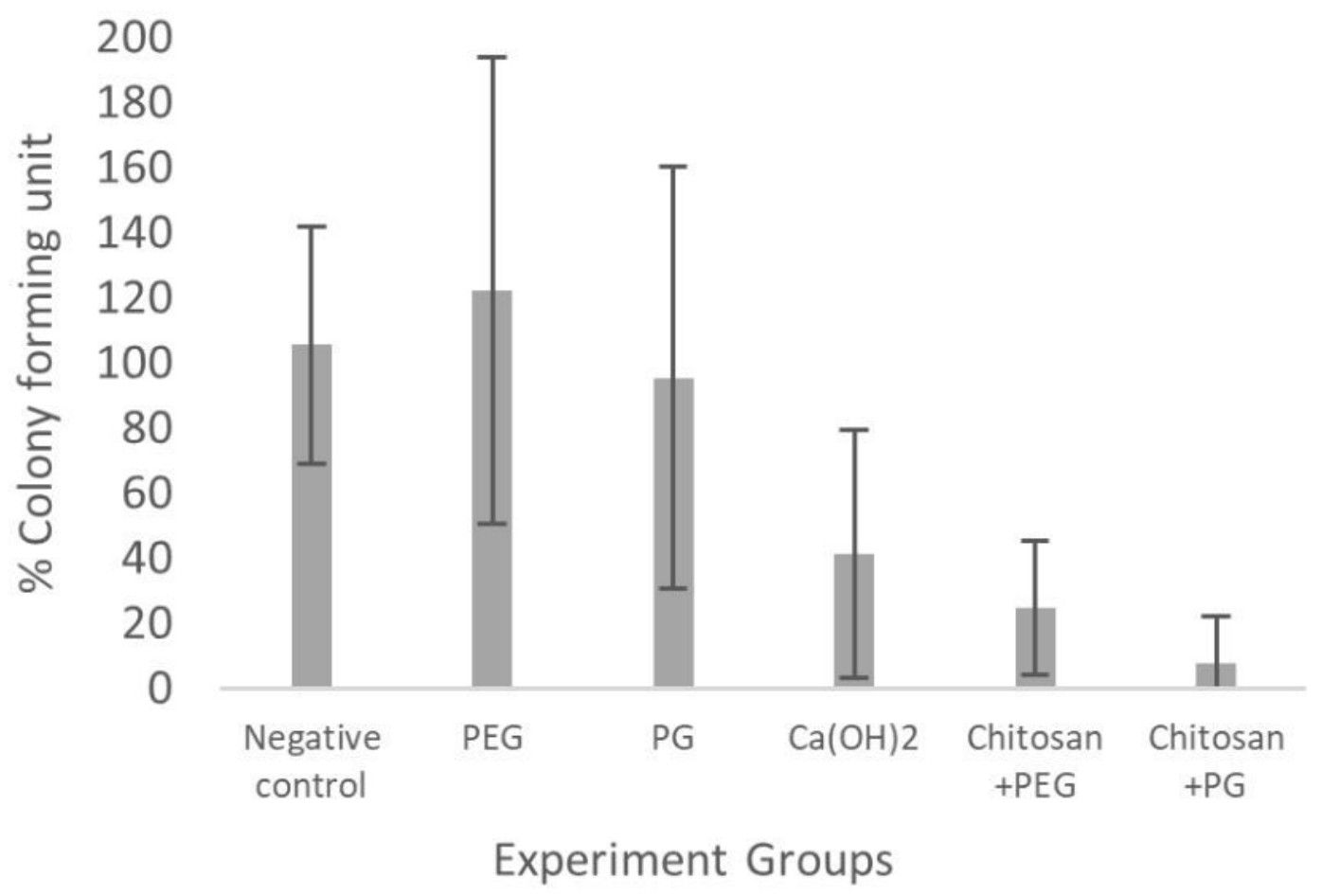

Fig 2

Figure 2

Percentage of remaining viable $C$. albicans after treatment with intracanal medication relative to negative control. Negative control group (105.40 $\pm 36.5 \%), 20 \%$ Polyethylene glycol (PEG) group $(122.06 \pm 71.7 \%)$, $20 \%$ Propylene glycol $(P G)$ group ( $95.36 \pm 64.8 \%)$, calcium hydroxide $\left(\mathrm{Ca}(\mathrm{OH})_{2}\right)$ group $(41.19 \pm 38.1 \%)$, chitosan+PEG group $(24.77 \pm 20.5 \%)$, chitosan+PG group $(7.57 \pm 14.6 \%)$

\section{Supplementary Files}

This is a list of supplementary files associated with this preprint. Click to download.

- supplementaryinformationfileBMCpasika.xlsx 